\title{
A IMPORTÂNCIA DO \\ PLANEJAMENTO PARA O \\ DESENVOLVIMENTO DO TURISMO SUSTENTÁVEL \\ NO PARQUE ESTADUAL DO GUARTELÁ - PARANÁ
}

THE IMPORTANCE OF PLANNING FOR THE DEVELOPMENT OF SUSTAINABLE TOURISM IN THE STATE PARK OF GUARTELÁ - PARANÁ

LA IMPORTANCIA DEL PLANEAMIENTO PARA EL DESARROLLO DEL TURISMO SOSTENIBLE EN EL PARQUE ESTATAL DE GUARTELÁ - PARANÁ

\section{Nivaldo Pereira da Silva}

nivaldopsilva@ig.com.br Universidade Tecnológica Federal do Paraná Mestre em Engenharia da Produção (UTFPR) Especialista em Gestão Industrial - Conhecimento e Inovação (UTFPR) Bacharel em Turismo (Faculdade Secal)

\section{Mayara Cristina Ghedini da Silva}

mayara_ghedini@hotmail.com Universidade Tecnológica Federal do Paraná Mestre em Engenharia da Produção (UTFPR) Especialista em Gestão Industrial - Produção e Manutenção (UTFPR) Bacharel em Secretariado Executivo (Faculdade Sant'Ana) 
Data de submissão: 01/06/2013

Data de aprovação: 17/03/2014

Resumo: O presente artigo tem como objetivo avaliar a importância do planejamento para o desenvolvimento do turismo sustentável no Parque Estadual do Guartelá - Paraná. Trata-se de um estudo de caso, cuja coleta de dados ocorreu por meio de visitas in loco e questionários aplicados aos turistas. Concluiu-se com este trabalho que os resultados alcançados ajudaram a compreender as motivações históricas que fomentaram a necessidade de conservação da paisagem, além da permanência da identidade cultural do lugar. A valorização da natureza e a preservação do ecossistema local incentivaram o município a lançar um novo olhar sobre seu patrimônio cultural e natural, visando a uma nova fonte de geração de renda para a população.

Palavras-chave: Planejamento. Turismo Sustentável. Patrimônio Natural.

Abstract: This article aims to evaluate the importance of planning for the development of sustainable tourism in the State Park Guartelá - Paraná. It is a case study, in which data were collected through site visits and questionnaires to tourists. It was concluded that the result have furthered understanding of the historical reasons that stimulated the need for conservation of the landscape, and the permanence of the cultural identity of the place. The appreciation of nature and the preservation of the local ecosystem encouraged the city to take a new look at its cultural and natural heritage, seeking a new source of income for the population.

Keywords: Planning. Sustainable Tourism. Natural Heritage. 
Resumen: El presente artículo tiene como objetivo evaluar la importancia del planeamiento para el desarrollo del turismo sostenible en el Parque Estatal de Guartelá - Paraná. Se trata de un estudio de caso cuya recolección de datos se llevó a cabo por medio de visitas in loco y cuestionarios aplicados a los turistas. Se concluyó con este trabajo que los resultados alcanzados ayudaron a comprender las motivaciones históricas que fomentaron la necesidad de conservación del paisaje, además de la permanencia de la identidad cultural del lugar. La valorización de la naturaleza y la preservación del ecosistema local incentivaron al municipio a lanzar una nueva mirada sobre su patrimonio cultural y natural, atrás de una nueva fuente de generación de renta para la población.

Palabras clave: Planeamiento. Turismo Sostenible. Patrimonio Natural.

\section{INTRODUÇÃO}

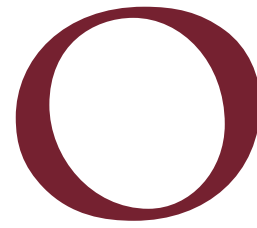

s recursos hídricos, até a década de 70, serviam exclusivamente ao lazer dos habitantes, sendo visitados principalmente pelos amantes da pesca, inclusive de arpão, com a anuência dos proprietários das fazendas. Atualmente, devido à mudança do comportamento social e às transformações dos valores e do estilo de vida da sociedade, o turismo representa uma importante fonte de riqueza em nossa economia. Ele gera empregos e receitas para empresas públicas e privadas, dispostas a desenvolvê-lo de forma profissional.

Com base nos principais autores sobre turismo em áreas naturais, percebese que a maioria dos estudos hoje produzidos enfoca as causas da evolução e a procura de espaços naturais para fins turísticos e recreativos, seguindo basicamente três linhas principais de debates: a) saturação do turismo convencional; b) desenvolvimento do paradigma ecológico; c) comercialização do "eco" e da "natureza", assumidos, por esta via, como bens de consumo. 
Alguns autores citam a recente evolução do turismo em áreas naturais, pois são fatores inerentes à conjuntura das novas tendências verificadas no segmento turístico, quer do lado da oferta, quer do lado da procura por Turismo de Natureza (VERA; PALOMEQUE; MARCHENA; ANTON, 1997).

Asatividadesturísticas, quandodesenvolvidasemáreasnaturais, podemtrazertanto benefícios como prejuízos, porém, faz-se necessário um planejamento consciente, para ordenar as ações do homem sobre o território, e para a preservação das áreas naturais por meio das estratégias de desenvolvimento turístico sustentável.

Nos últimos anos, surgiram várias modalidades de turismo, que interagem entre si, tais como: Ecoturismo; Turismo de aventura; Turismo rural; Turismo histórico-cultural; Turismo técnico-científico e Turismo pedagógico.

De acordo Swarbrooke (2000), é necessário satisfazer os desejos do turista, das comunidades locais, sem comprometer a capacidade das futuras gerações de satisfazerem suas próprias necessidades. Desta forma, turismo em áreas naturais é aquele que ocorre em harmonia com a natureza e que visa à conservação dos recursos naturais para as futuras gerações. Sendo assim, este trabalho busca responder: Qual a importância do planejamento para o desenvolvimento do turismo sustentável no Parque Estadual do Guartelá?

O turismo em áreas naturais apresenta vários benefícios para o ambiente natural, pois, conforme Swarbrooke (2000, p.14), ele estimula uma compreensão dos impactos do turismo nas áreas ambientes naturais, culturais e humano, além de incorporar o planejamento para assegurar o desenvolvimento do turismo adequado à capacidade de carga do ecossistema, assim demonstrando a importância dos recursos naturais e culturais e poder ajudar a preservá-los.

Entre os aspectos positivos do segmento de turismo em áreas naturais é que o mesmo contribui para a divulgação do local, estimulando o deslocamento de pessoas para visitá-lo e também incentiva a criação de decretos e leis, visando à elaboração e à execução de programas no intuito de desenvolver a atividade turística e, ao mesmo tempo, garantir a preservação da área.

Frente a este contexto, o presente trabalho tem como objetivo avaliar a importância do planejamento para o desenvolvimento do turismo sustentável no Parque Estadual do Guartelá - Paraná. 


\section{SIGNIFICADO DE TURISMO EM ÁREAS NATURAIS}

O turismo em áreas naturais pode ser compreendido como um segmento que se desenvolve de forma sustentável, e que proporciona altos índices de crescimento, o que é uma tendência atual. Isso implica uma demanda crescente de turistas em busca de um maior contato com a natureza.

Para Vera, Palomeque, Marchena e Anton (1997 p.143), é pertinente uma definição como forma de designar todas as modalidades que se baseiam em contato, direto ou indiretamente com o meio ambiente, sendo o ponto central da oferta turística e que se sintetizam na expressão "turismo em espaços naturais".

Corroborando com a definição acima, o turismo em áreas naturais proporciona admirá-lo, estudá-lo e interpretar as plantas e os animais, bem como as marcas culturais do passado, para ordenar as ações do homem sobre o território, a fim de evitar que este cause danos irreparáveis ao meio ambiente.

Embora a definição de turismo em áreas naturais seja consideravelmente nova, cada autor tende a avançar com o seu próprio conceito, Lucas (1984 apud Weiler, 1992 p.108) afirmava que o Turismo em áreas naturais é um segmento de turismo que se baseia em diversas atividades em áreas naturais e na observação da natureza, sendo responsável por minimizar os impactos ambientais e por otimizar os impactos sociais e econômicos para o país ou região.

No entanto, por mais que se minimizem os impactos negativos, o turismo também traz danos ambientais, pois só com a presença dos visitantes nos destinos turísticos pode ocorrer o aumento do lixo, a poluição da água e do solo, entre outros. Uma atividade mais intensa pode causar a alteração da flora e da fauna da área, comprometendo-se na construção meios de hospedagens. E pelo fato de as árvores servirem de abrigo para a fauna local, esta também é afetada. Para Ignarra (2003), a procura dos aspectos diferenciais da paisagem são elementos mais diferenciados e mais valorosos, e que provocam concentrações de turistas ou de serviços turísticos no seu entorno. Estas concentrações, além de interferirem na paisagem local, provocam outros impactos. 
A atividade turística, quando é desenvolvida sem o seu controle e planejamento, passa a "explorar" o local, causando degradação e danos em suas características intrínsecas. Um olhar mais atento sobre as regiões em estudo permite identificar os pontos comuns para a definição das atividades, para integrar as categorias de manejo que protegem toda a diversidade de ecossistemas do país, bem como a diversidade de ambientes cênicos e de belezas naturais, o patrimônio genético, as espécies raras ou em perigo de extinção, e outros aspectos naturais e culturais (REVISTA VISÃO E AÇÃO, 2000, p. 65).

Todo o planejamento deve ser direcionado ao comportamento dos turistas, para a educação ambiental e como geradora de benefícios, tanto econômicos, quanto ambientais, pois segundo Ruschmann (1997), é importante o desenvolvimento do turismo em áreas naturais, conforme elencados a seguir:

a) Desenvolver o turismo em regiões rurais e naturais, principalmente fora dos grandes centros urbanos, podendo ser desenvolvido em espaços naturais protegidos tais como parques nacionais e naturais.

b) Subsidia o desenvolvimento das precárias economias rurais.

c) A oferta turística é de baixo impacto ambiental, porém deve existir uma preocupação adicional com a natureza e com a população local;

d) Os atrativos turísticos não se concentram todos no mesmo local;

e) O ecoturismo auxilia na descoberta da realidade envolvente, tanto a cultural como a natural, sendo muito comum o desenvolvimento de atividades lúdicas e educativo-culturais.

Opondo-se à hegemonia de outros segmentos de turismo (turismo convencional), este tipo de turismo pretende assumir a garantia de conservação da natureza e respeitador do meio ambiente. 


\section{PLANEJAMENTO TURÍSTICO}

O planejamento é uma ferramenta importante para organizações do trade turístico. Segundo a Paranatur, "Planejamento" é o processo permanente de reflexão e análise para a escolha de alternativas que permitam alcançar determinados resultados desejadas no futuro, pode-se salientar que o planejamento é a base para o desenvolvimento da atividade turística.

Ruschmann (1997, p. 37) e Ansarah (2001, p. 66) salientam a importância do planejamento para uma localidade de forma fundamental e indispensável para o desenvolvimento turístico equilibrado e em harmonia com os recursos físicos, culturais e sociais das regiões receptoras, evitando que o turismo destrua as bases que o fazem existir, com vistas em um desenvolvimento da atividade turística e, consequentemente, para todas as destinações, consistindo um conjunto de atividades que envolvem a intenção de estabelecer condições favoráveis para alcançar os objetivos propostos.

\section{ETAPAS DO PLANEJAMENTO}

O planejamento envolve várias etapas, porém Barretto (2000, p. 27) salienta que "a primeira mudança recomendada no processo de planejamento é a mais simples, é passar da não-existência do planejamento à decisão de planejar". A decisão de planejar envolve várias motivações, sejam do ponto de vista econômico ou de um ponto de vista mais abrangente, como as necessidades conjunturais, exigência de agências financiadoras, necessidade de administrar melhor os recursos escassos. 
Quadro 1 - Etapas do planejamento

\begin{tabular}{|c|c|c|}
\hline Item & Etapa & Ações \\
\hline 1 & Análise macroambiental & $\begin{array}{l}\text { Conhecer o entorno da organização, o mercado e a } \\
\text { situação interna. }\end{array}$ \\
\hline 2 & Elaboração de diagnóstico & $\begin{array}{l}\text { Sumário que reflete os levantamentos da análise } \\
\text { macroambiental. }\end{array}$ \\
\hline 3 & Definir os objetivos & O que se quer atingir. \\
\hline 4 & Determinar as prioridades & $\begin{array}{l}\text { O que é mais importante. } \\
\text { Em que ordem. }\end{array}$ \\
\hline 5 & $\begin{array}{l}\text { Identificar os obstáculos, as } \\
\text { dificuldades }\end{array}$ & $\begin{array}{l}\text { Listar quais são. } \\
\text { Sua intensidade. } \\
\text { Influência sobre os resultados. }\end{array}$ \\
\hline 6 & $\begin{array}{l}\text { Criar os meios, os } \\
\text { mecanismos }\end{array}$ & $\begin{array}{l}\text { Visam minimizar obstáculos. } \\
\text { Analisar e escolher alternativas. }\end{array}$ \\
\hline 7 & $\begin{array}{l}\text { Dimensionar os recursos } \\
\text { necessários }\end{array}$ & $\begin{array}{l}\text { Quantificar os recursos. } \\
\text { Em que ordem de necessidade. }\end{array}$ \\
\hline 8 & $\begin{array}{l}\text { Estabelecer } \\
\text { responsabilidades }\end{array}$ & Especificar volumes, padrões fluxos, áreas críticas etc. \\
\hline 9 & Projetar cronograma & $\begin{array}{l}\text { Definir prazos de execução, volume de produção, custos, } \\
\text { parâmetros, etc. }\end{array}$ \\
\hline 10 & $\begin{array}{l}\text { Estabelecer pontos de } \\
\text { controle }\end{array}$ & $\begin{array}{l}\text { Escolher áreas-chave. } \\
\text { Estabelecer critérios. }\end{array}$ \\
\hline
\end{tabular}

Fonte: PETROCCHI, M. (1998, p. 51).

Com base no Quadro 1, elaborado por Petrocchi (1998, p. 51), pode-se afirmar que o planejamento segue algumas etapas: análise macroambiental, em seguida prevê o diagnóstico, a escolha e a delimitação do tema, e decide o que planejar.

A análise macroambiental é naturalmente extensa. Por isso, o roteiro do planejamento prevê o diagnóstico, que é um sumário da situação analisada. Ele dá, em poucas palavras, a situação de mercado - oportunidades e ameaças - e sintetiza os atrativos turísticos, os pontos fortes e fracos desse sistema. $O$ diagnóstico é, assim, uma síntese da situação atual, sendo muito importante para a comunicação sobre o processo de planejamento. 
Desse modo, considera-se importante o diagnóstico da situação social, econômica, cultural, política e ambiental do local onde será realizado o planejamento turístico. Também é importante saber qual o tipo de turismo que se pretende desenvolver, visando à formulação de objetivos de acordo com a realidade e com maiores possibilidades dos mesmos serem atingidos.

De acordo com o Quadro 1, identificam-se as características do local para realizar o planejamento, buscando-se e avaliando-se as possibilidades de intervenção. Toma-se a decisão de intervenção e de ação e controla-se.

Com base nas etapas do planejamento descritas anteriormente, pode-se observar que o planejador do turismo precisa ter uma visão global (econômica, sociocultural e ambiental) da realidade na qual pretende intervir, trabalhar com uma equipe multidisciplinar, identificar as variáveis dependentes e as variáveis independentes e relacioná-las, comunicar os objetivos e possibilitar a participação de todas as pessoas envolvidas no processo.

\section{PLANEJAMENTO SUSTENTÁVEL}

Para Ruschmann (1997, p. 75), o planejamento sustentável refere-se a um turismo brando, suave, qualitativo, alternativo, responsável, que prevê uma visão administrativa moderna e contínua. Assim, o planejamento sustentável é aquele que atende às necessidades dos turistas atuais, sem comprometer a possibilidade do usufruto dos recursos pelas gerações futuras.

Importante salientar a necessária perpetuação da atratividade dos recursos turísticos, pois o planejamento é a base do desenvolvimento sustentável. Para tal, Seaton, citado por Ruschmann (1997, p. 95), aponta as características específicas. A primeira refere-se ao respeito ao meio ambiente natural, não o agredindo; a harmonia entre a cultura e os espaços sociais da comunidade, sem agredi-la ou transformá-la; a distribuição equitativa dos benefícios entre a comunidade receptora, os turistas e os empresários do setor. A última refere-se a um tipo de turista mais responsável, atencioso e educado, respeitando a localidade que visita.

Segundo Ansarah (2001, p. 30), o turismo deve ser estudado e direcionado para o desenvolvimento sustentável, sendo o conceito eficaz para alcançar metas 
de desenvolvimento sem esgotar os recursos naturais e culturais nem deteriorar o meio ambiente. Ainda, segundo a mesma autora, entende-se que a proteção do meio ambiente e o êxito do desenvolvimento turístico são inseparáveis.

Saliente-se que o turismo sustentável é aquele que ocorre em harmonia com a natureza, visando à conservação dos recursos naturais para as gerações futuras. O turismo sustentável apresenta vários benefícios para o ambiente natural.

Para Swarbrooke (2000, p.14), é importante instigar a compreensão dos impactos do turismo nos ambientes naturais e culturais, sendo necessário incorporar o planejamento e o zoneamento para assegurar o desenvolvimento do turismo adequado à capacidade de carga do ecossistema, dessa forma, demonstrando a importância dos recursos naturais e culturais e podendo ajudar a preservá-los. Portanto, o planejamento sustentável deve garantir a proteção dos recursos naturais e também ser fonte geradora de renda.

\section{ÁREA DE ESTUDO}

Tibagi é um município localizado às margens do Rio Tibagi, sendo o maior município em extensão territorial do Estado do Paraná. Sua formação aconteceu somente na última década do século XVIII por Antônio Machado Ribeiro, vulgo Machadinho, que veio de São Paulo em 1782.

Desde os tempos mais distantes a região era conhecida por possuir ouro e uma enorme quantidade de pedras preciosas, principalmente diamantes, sendo este o principal motivo das numerosas expedições na região, desde os primeiros tempos das entradas no sertão feitas pelos bandeirantes paulistas.

A cidade foi fundada por portugueses, mas aos poucos teve sua população enriquecida com a presença dos mestiços resultantes do cruzamento entre brancos, índios e negros, e mais recentemente pelos imigrantes holandeses, vindo dos municípios de Carambeí e Castro.

PARQUE ESTADUAL DO GUARTELÁ

O parque estadual do Guartelá foi criado em 1992, com o objetivo de preservar os ecossistemas típicos da região do Cânion do Rio Iapó ou Cânion Guartelá. A 
região possui belas paisagens, lugares misteriosos, formações rochosas, como a Cachoeira da Ponte de Pedra, os "Panelões do Sumidouro" e o Rio Iapó, que corta o desfiladeiro.

"Guartelá" é uma lenda regional, que significa "Guarda-te-lá que cá bem fico", usada por um morador da região para alertar seu "compadre" sobre o ataque dos índios. Nos cânions do Rio Iapó há muitos registros da história, da cultura e das tradições da região. As formações rochosas ainda guardam a marca de seus primeiros moradores, as pinturas rupestres.

\section{ATRATIVOS}

O turismo é um elemento que proporciona uma apetência suscetível de motivar o deslocamento de pessoas para conhecê-los. Como registra Beni (2003, p. 303), "todo lugar, objeto ou acontecimento de interesse turístico que motiva o deslocamento de grupos humanos para conhecê-los", podendo ser bens de patrimônio naturais quando é obra da própria natureza, ou bens de patrimônio histórico cultural quando criadas ou promovidas pelo homem.

Corroborando com a citação de Beni, os recursos atrativos naturais são elementos localizados no espaço físico-geográfico, e que constituem a paisagem, ligados à natureza e que muitas vezes são valorizados por meio de infraestrutura construída pelo homem, sejam visando à proteção ambiental ou à visitação turística.

Importante ressaltar que os recursos naturais hoje são um produto turístico de suma importância para a localidade receptora. Porém, existe uma preocupação com o uso irracional desses recursos pela atividade do turismo nos dias atuais, principalmente nos atrativos turísticos da região: Rappel na cachoeira; Paredão do Guartelá; Rio Iapó; Salto Santa Rosa; Rapel na Cachoeira Puxa Nervos; Rio Tibagi; Morro do Jacaré ou Pedra Branca; Turismo e Ecoturismo.

São obras criadas pelo homem ou obras conjuntas do homem e da natureza, incorporando-se à paisagem. Segundo Beni (2003, p. 308), são manifestações sustentadas por elementos materiais que se apresentam sob a natureza. 


\section{PROCEDIMENTOS METODOLÓGICOS}

O presente trabalho, do ponto de vista dos procedimentos técnicos, classificase como um estudo de caso, que segundo Yin (2005), trata-se de uma forma de se fazer pesquisas investigativas dentro de um contexto real. Complementando a afirmação anterior, Gil (1991) afirma que estudo de caso é o estudo exaustivo de poucos objetivos, com a finalidade de gerar conhecimentos amplo e específico sobre o tema pesquisado.

A pesquisa foi realizada no Parque Estadual do Guartelá, que está localizado no município de Tibagi, por meio de visitas in loco e aplicação de questionários aos turistas. O estudo foi elaborado entre os meses de Janeiro a Abril de 2013, quando foi aplicado um total de quinhentos questionários aos turistas que visitaram o parque no período pesquisado. Por sua vez, a escolha dos respondentes ocorreu de forma aleatória e por acessibilidade.

Utilizou-se o método descritivo estatístico para responder às questões quantitativas, e apresentar os resultados analisados e interpretados a partir de médias e percentuais das respostas obtidas.

\section{ANÁLISE DOS RESULTADOS}

Este estudo visa mostrar a necessidade do planejamento para o desenvolvimento do turismo sustentável em áreas naturais, pois hoje o Parque Estadual do Guartelá - Paraná concentra uma grande quantidade de atrativos de expressão nacional. 


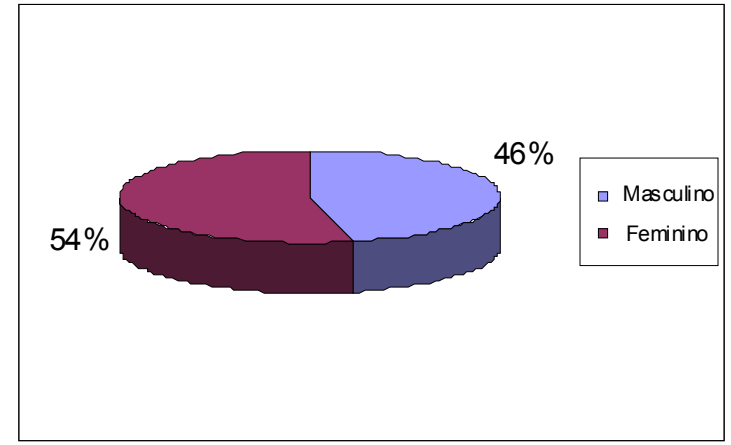

O Gráfico 01 mostra que mais da metade dos entrevistados são do sexo feminino. Este número deve-se a uma considerável quantidade de jovens (mulheres - moças) viajando. Em alguns casos as mulheres respondem o questionário pelo casal, mas avós e filhas adolescentes, fazendo parte do contexto familiar.

Gráfico 02 - Qual o país que o turista reside?

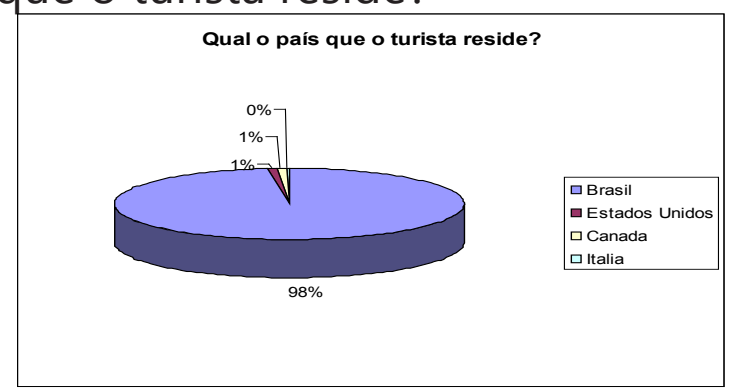

No Gráfico 02, percebe-se que $98 \%$ dos turistas que visitam o Parque Estadual do Guartelá são brasileiros. A procedência dos visitantes é um importante indicador das áreas protegidas no contexto regional. Neste caso, o padrão natural de visitantes residentes nas proximidades do Parque.

Gráfico 03 - Qual estado o turista reside?

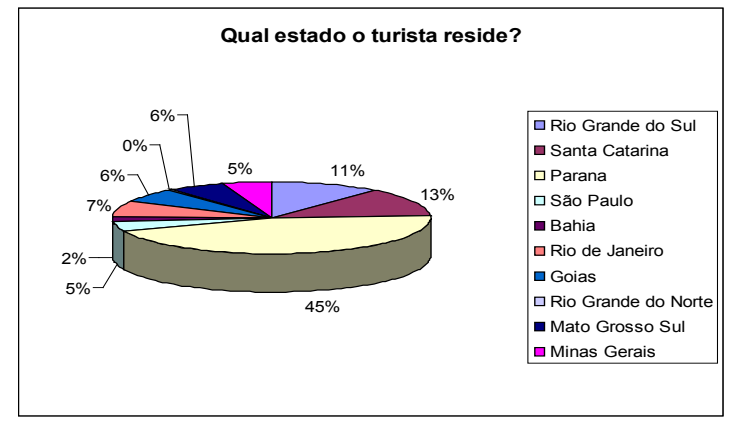


No Gráfico 03, observa-se que a maioria dos turistas que visita o Parque é do Paraná, Santa Catarina e Rio Grande do Sul, porque o atrativo está geograficamente mais próximo dessas regiões, ganhando inclusive da Região Sudoeste (São Paulo, Minas Gerais e Rio de Janeiro). Pode-se observar que os resultados apresentam turistas de estados da Região Centro Oeste.

Gráfico 04 - Você já conhecia a cidade?

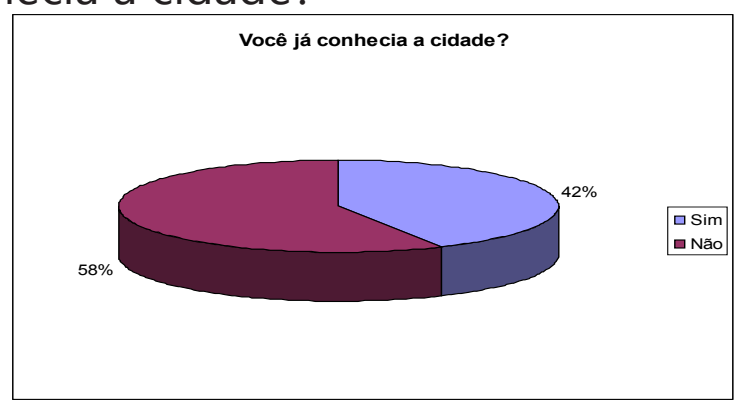

No Gráfico 04, no questionamento quanto a ser a primeira vez da visita ao ponto turístico, mostra que o turista em $57,8 \%$ não conhecia a cidade. A análise demonstra o interesse do turista pela cidade.

Gráfico 05 - Qual motivo lhe trouxe à cidade?

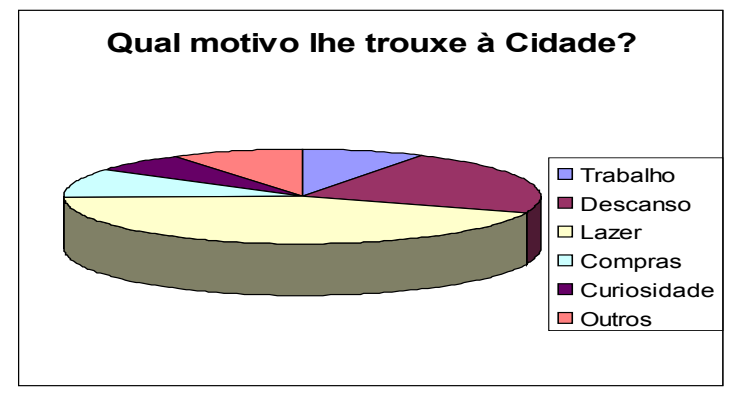

No Gráfico 05, neste questionamento, registra-se que 44,2\% dos turistas procuram a cidade para o lazer. É importante destacar que, hoje, o turista procura uma localidade turística para lazer. Portanto, é necessário um lazer bem planejado, atingindo as reais necessidades do ser humano.

No complemento da pergunta, qual o motivo Ihe trouxe à cidade? Obtiveram-se "outros motivos" com 8,8\%, o que representa 44 (quarenta e quatro) turistas no universo de 500 (quinhentas) pessoas entrevistadas, como os seguintes motivos: 18 (dezoito) a negócios e 26 (vinte e seis) vão a Tibagi para rever a família. 
Gráfico 06 - Como você classificaria de uma forma geral a infraestrutura dos atrativos turísticos?

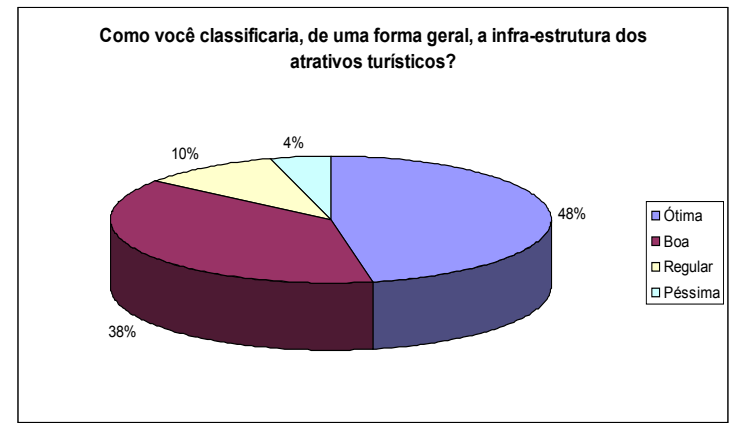

Na análise do Gráfico 06 , verifica-se que $48 \%$ dos turistas classificam como ótima a infraestrutura dos atrativos e $38 \%$ se manifestou satisfeita (boa) com a qualidade da infraestrutura dos atrativos turísticos. Dentro deste percentual se torna mais significativa esta avaliação, pois o somatório dos conceitos Ótimos e Bons ficou acima de $50 \%$, sendo bastante favorável o resultado, pois este dado é referente aos principais itens de infraestrutura dos atrativos.

Gráfico 07 - Como você avalia a qualidade dos serviços prestados nos hotéis, restaurantes, etc.?

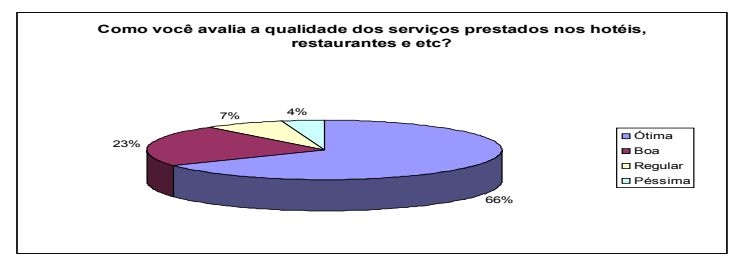

No Gráfico 07, observa-se que a maioria dos turistas questionados na pesquisa se manifestou de forma satisfeita com a qualidade dos serviços hoteleiros, de restaurantes, entre outros, de que se utilizou, sendo que $89 \%$ dos entrevistados deram conceitos entre ótimo e Bom.

Gráfico 08 - Quanto à receptividade da população local?

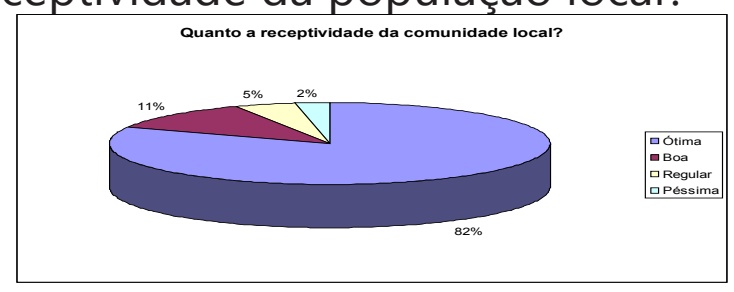


No Gráfico 08, este item demonstra que a comunidade local está aberta para recepcionar o turista, possibilitando uma estada agradável na região. A pesquisa evidenciou que os moradores da área contemplada apresentam uma alta receptividade, assim como expectativas muito otimistas em relação ao Parque Estadual do Guartelá. Este comportamento, que pode em princípio ser considerado positivo, implica também a responsabilidade dos gestores no sentido de equacionar soluções que contemplem tais demandas, com o objetivo de manter a amistosidade no relacionamento com a comunidade e compartilhar com a mesma os benefícios da exploração do turismo.

Gráfico 09 - Quanto aos preços praticados na cidade (hotéis, restaurantes, locais turísticos, souvenirs, etc.)?

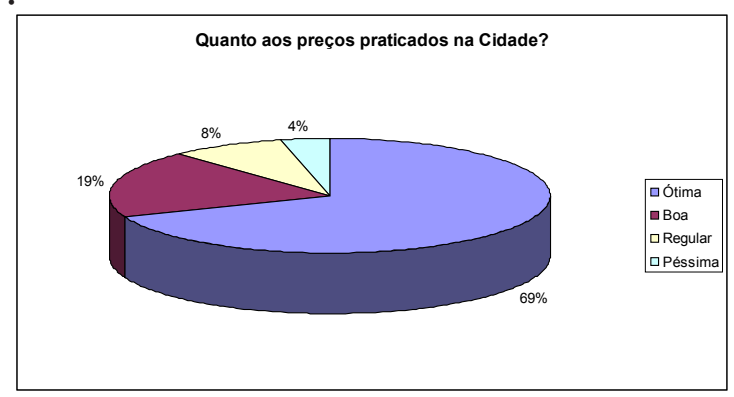

No Gráfico 09, nota-se que os preços praticados na região estão dentro do padrão, com 69\% dos turistas respondendo que são ótimos e 19\% dos turistas afirmaram que estão bons. Segundo Ruschmann (1997, p. 75), as comunidades sentem orgulho de sua localidade, engajam-se nas campanhas preservacionistas e passam a atuar como guias dos passeios dos turistas.

Gráfico 10 - Quanto à limpeza da cidade, conservação e paisagismo?

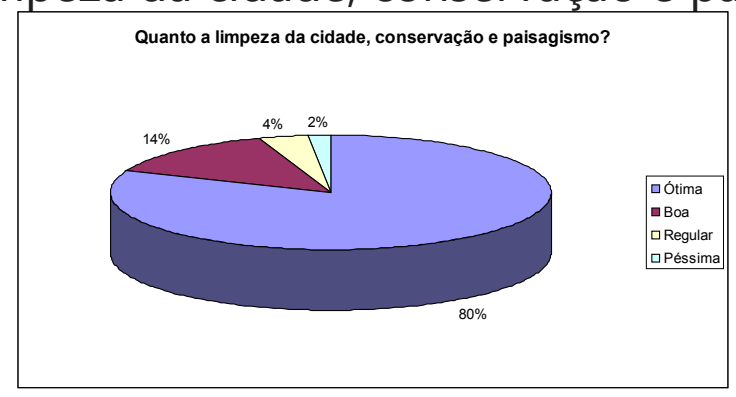

No Gráfico 10, observa-se que, no quesito quanto à limpeza da cidade, à conservação e ao paisagismo, os turistas consideraram ótimo, com 80\%; e 14\% responderam que estão bons. O centro da Cidade de Tibagi, que tem maior 
tráfego de pessoas e comércio mais intenso, faz com que a limpeza seja mais sistematizada, devido a maior quantidade de dejetos produzidos. Também por concentrar a rede hoteleira, e outros meios de hospedagem, o que coloca o turista em contato direto com o dia a dia da cidade.

\section{CONCLUSÕES}

Tibagi retrata a beleza e a imponência, porém ela não é completa, pois o homem também promoveu grandes mudanças, tornando a cidade um imenso complexo turístico, sendo atraente quer seja pelo modelo de cidade organizada, de belezas artificiais e naturais, sua arquitetura, mas também é impossível negar que ela não tenha, como tantas outras cidades brasileiras, os problemas sociais, econômicos, ambientais e políticos que se traduzem de forma negativa para o desenvolvimento do turismo.

Hoje a cidade busca o envolvimento de todos os setores da comunidade, pois depende do desempenho dos diversos setores envolvidos, sejam públicos ou privados, para se tornar um dos principais destinos turísticos do Brasil.

Tendo como objetivo central avaliar a importância do planejamento para o desenvolvimento do turismo sustentável no Parque Estadual do Guartelá Paraná, o presente trabalho concluiu que há necessidade de um planejamento com propostas de ações estratégicas para o desenvolvimento do turismo de natureza sustentável, pois o turismo sustentável promove a ordenação dos espaços, dos equipamentos e das atividades turísticas, gerando renda e contribuindo para a preservação dos recursos naturais, e garantindo a conservação e a proteção dos atrativos por meio do controle dos turistas.

Percebe-se que as áreas protegidas se constituem um dos principais instrumentos para garantir a continuidade de espaços naturais primitivos, ou seja, sem a ação do homem.

O Turismo Sustentável deve ser uma ferramenta que, além de conservar as áreas naturais, pode auxiliar economicamente nas melhorias das áreas e também ajudar a conscientizar as pessoas da importância do planejamento 
ordenado para evitar danos ambientais. E quanto à infraestrutura dos atrativos e à qualidade dos serviços prestados, pode-se afirmar que a cidade está se preparando para concorrer como centro receptor de turistas.

\section{REFERÊNCIAS}

ANSARAH, Marília Gomes dos Reis (Org.). Turismo. Como aprender, como ensinar. São Paulo: Editora SENAC, 2001.

BARRETO, Margarita. Turismo e legado cultura. Campinas, SP: Papirus, 2000.

BENI, Mário Carlos. Análise estrutural do turismo. 9. ed. São Paulo: Editora Senac São Paulo, 2003.

GIL, Antônio Carlos. Como elaborar projetos de pesquisa. 3. ed. São Paulo: Atlas, 1991.

IGNARRA. Luiz Renato. Fundamentos do Turismo. 2. ed. São Paulo: Pioneira Thomson Learning, 2003.

LAKATOS, E. M.; MARCONI, M. A. Metodologia científica. 2. ed. São Paulo: Atlas, 1991.

PETROCCHI, Mario. Turismo Planejamento e Gestão. 7. ed. São Paulo: Ed. Futura, 1998

REVISTA VISÃO E AÇÃO. Universidade do Vale do Itajaí. Ano 2, nº 4. Itajaí: Editora da Univali, 2000.

RUSCHMANN, D. van de Meene. Turismo e Planejamento Sustentável: A Proteção do meio ambiente. São Paulo: Papirus, 1997.

SWARBROOKE, J. Turismo Sustentável: conceitos e impacto ambiental. São Paulo: Aleph, 2000.

VERA, J. F.; PALOMEQUE, F. L.; MARCHENA, M. J.; ANTON, S. Análisis territorial del turismo: uma nueva geografia del turismo. Barcelona: Ariel, 1997.

YIN, R.K. Estudo de caso: planejamento e métodos. 3. ed. Porto Alegre: Bookman, 2005. 